\title{
Chronic sources of low cocoa production in Ghana: new insights from meta-analysis of old survey data
}

\author{
Francis Tsiboe ${ }^{\star}($ D) \\ Department of Agricultural Economics, Kansas State University, Manhattan, KS, USA \\ ${ }^{*}$ Corresponding author. Email: ftsiboe@hotmail.com
}

(Received 14 March 2020; revised 2 February 2021; accepted 3 February 2021)

\begin{abstract}
Several studies have tried to estimate the productivity and input use efficiency of cocoa farmers in Ghana, but they shed limited light on their chronic nature and other sources of low production. This study extends the literature by analyzing a unique nationally representative sample that constitutes 30 years of production. The results showed that pure farmer technical inefficiency is not only 8 percent points larger than the regional technology gap, but also consistently dominated the overall performance of farmers from 19872017. The policy implication of this finding at face value suggests that improving farmer managerial skills could increase output.
\end{abstract}

Keywords: cocoa; Ghana; technical inefficiency; technology gap

JEL codes: D24; Q18; Q12

\section{Introduction}

Since its introduction in Ghana in the 1880s, cocoa (Theobroma cacao) has transformed the country's agricultural sector and plays a significant role in the Ghanaian economy. In Ghana, cocoa provides approximately GHC 2,500 in annual sales revenue for its over 500,000 producing households in 2016/2017 (Ghana Statistical Service (GSS) 2019) and accounted for 16 percent of 2010/2019 exports (UN Comtrade 2020). As a result, cocoa has historically been branded as Ghana's "engine of economic growth". Based on data from FAOSTAT, Ghana's share in global cocoa production peaked at about 38 percent in 1964/1965, making the country the largest cocoa producer globally for that season. About half a century later, Ghana's share declined by about 50 percent to only 19 percent during the 2015/2016 season, making it the second-largest producer globally after the Ivory Coast. The decline in Ghana's cocoa production in the 1960s has generally been attributed to price and exchange rate distortions in the country's cocoa and agricultural sector, poor maintenance culture, depletion of soil nutrients, and biotic and abiotic stress (Kolavalli and Vigneri 2017).

(c) The Author(s) 2021. Published by Cambridge University Press on behalf of the Northeastern Agricultural and Resource Economics Association. This is an Open Access article, distributed under the terms of the Creative Commons Attribution licence (http://creativecommons.org/licenses/by/4.0/), which permits unrestricted re-use, distribution, and reproduction in any medium, provided the original work is properly cited. 
Following the decline in production in the 1960s, coupled with a general collapse of its economy, the Government of Ghana (GoG) implemented several policies and reforms to recover its cocoa sector (these are enumerated in the literature section). Notwithstanding the recovery from these efforts, data from FAOSTAT show that the mean cocoa yield of $393 \mathrm{~kg} / \mathrm{ha}$ was about 24 percent below global standards from 1990 to 2015. ${ }^{1}$ This implies that there is still room to further improve cocoa yields in Ghana. The World Bank has also asserted that total factor productivity dictates the performance of agriculture and that agricultural performance is also strongly linked to the growth of developing countries (World Bank 2007). Thus, it is important to investigate the productivity of existing input resources and how they are used efficiently. Accordingly, several peer-reviewed studies have tried to estimate the productivity and technical efficiency (TE; i.e., how well inputs are used) of cocoa farmers in Ghana. These studies show that Ghanaian cocoa farmers using conventional production methods produced at 44-85 percent TE levels (Binam, Gockowski, and Nkamleu 2008; Aneani et al. 2011; Ofori-Bah and Asafu-Adjaye 2011; Onumah et al. 2013; Besseah and Kim 2014; Danso-Abbeam and Baiyegunhi 2019). However, these estimates encompass production and practices for a single season, and as such, they shed limited light on the chronic nature of technical inefficiency and other sources of low production in Ghana's cocoa sector.

This study borrows the term "chronic" from the poverty literature where it is used to describe the phenomenon whereby a state of poverty extends over multiple periods. In this regard, a chronic source of low production is one that consistently dampens production levels over multiple seasons. Previous studies have identified technological gaps and pure farmer technical inefficiency as phenomena that contribute to low production levels for cocoa (Binam, Gockowski, and Nkamleu 2008; Danso-Abbeam and Baiyegunhi 2019) and other crops (Tsiboe, Asravor, and Osei 2019) in Ghana. However, it remains to be determined which of the two phenomena is chronic. Given the host of policies already implemented in Ghana's cocoa sector and the yield shortfall below global standards, ascertaining the chronic nature of these two phenomena can clear up uncertainty on whether future farm policy should be geared toward introducing new technologies, enhancing existing technology, or improving the efficiency with which existing technologies are used (Danso-Abbeam and Baiyegunhi 2019).

Considering the foregoing premise, the main objective of this article is to ascertain the spatiotemporal heterogeneity in Ghanaian cocoa production technology and efficiency by accommodating multiple seasons and heterogeneity in regional cocoa technology in Ghana. Particularly, this study applies a meta-stochastic frontier analysis to data from 19 cross-sectional surveys fielded in Ghana for 20 growing seasons between 1987 and 2017 that covers all cocoa-growing regions in the country. The rich nationally representative dataset has the widest coverage of cocoa households across time and space than any of the previous studies conducted on Ghana. As such, it presents a unique opportunity to empirically assess the spatial distribution and temporal dynamics in cocoa production parameters (elasticities, returns to scale (RTS), technological gaps, and productivity trends) and the efficiency with which existing technology is used.

The results showed that pure farmer technical inefficiency was 8 percent points larger than the regional technology gap and consistently dominated the overall

\footnotetext{
${ }^{1}$ The global standard is taken as the mean yield of the top eight (excluding Ghana) cocoa producers globally; Ivory Coast, Indonesia, Nigeria, Cameroon, Brazil, Ecuador, and Malaysia; in that order.
} 
performance of farmers relative to the industrial frontier from 1987 to 2017. This suggests that between the two, regional pure farmer technical inefficiency is a chronic source of low cocoa production in Ghana. The policy implication of this finding at face value suggests that improving farmer managerial skills could increase output. However, such a blanket policy will not be appropriate for farmers in all regions. Brong Ahafo and Ashanti regions performed poorly relative to the national production frontier mainly because of technology gaps, and on the contrary, the Western and Central regions performed poorly due to pure farmer technical inefficiency. This suggests that the first group could benefit from technology distribution, and the second would benefit from training in good cocoa production practices.

\section{Literature review}

\section{Ghana cocoa sector recovery}

The recovery process for Ghana's cocoa sector following the 1960s' decline started with the Economic Recovery Program in 1983, followed by: the establishment of the Producer Price Review Committee and the implementation of the Structural Adjustment Program in 1984; the introduction of Licensed Buying Companies (LBCs) in 1993; the privatization of LBCs in 1999; and the initiation of Higher Technology ("HI-TECH"), Cocoa Diseases and Pests Control (“CODAPEC”), and the concept of the net "Free On Board" between 2001 and 2004 (Kolavalli and Vigneri 2017). Except for the HI-TECH and CODAPEC programs, most of these policies were aimed at increasing the share of export price passed on to farmers and liberalizing the cocoa economy in Ghana. As for the HI-TECH and CODAPEC programs, the GoG via the Ghana Cocoa Board (COCOBOD) supported cocoa producers with education on good and improved agronomic practices, the provision of subsidized inputs, and mass spraying of farms with agrochemicals to control pest and diseases.

The main aim of HI-TECH and CODAPEC is to increase cocoa production without increasing its cultivated area. While each of the policies and reforms has their level of success and failure, their net effect has led to cocoa production levels that exceed that of the 1960s, peaked at one million tons in 2010, and stabilized around 850,000 tons annually between 2011 and 2016 (Kolavalli and Vigneri 2017; Food and Agriculture Organization (FAO) 2019). Aside from the GoG-led policies and reforms, nongovernmental organizations have also deployed several programs to improve cocoa yields and the livelihoods of cocoa-producing households (World Cocoa Foundation 2018). Several studies have shown that the NGO-led programs have also improved farmer-level yields and welfare (Opoko et al. 2009; Gockowski et al. 2010; Norton et al. 2013; Tsiboe et al. 2016, 2018b).

\section{Previous Ghanaian studies}

The implemented policies and reforms by GoG and NGOs have indeed led to improvements in Ghana's cocoa yields. However, current yields are 24 percent below global standards. The extent to which this shortfall could be attributed to productive efficiency for singleton seasons is well established by previous studies. For example, Binam et al. (2008) evaluated the production TE of cocoa farmers across West and Central Africa by applying the stochastic meta-production frontier to survey data collected in 2001/2002. Their results showed that Ghanaian cocoa farmers were operating at 44 percent of their 
potential productive capacity and that farmer gender, access to credit and agricultural extension, and the amount of canopy shade in the farm had significant effects on TE. While Binam et al. (2008) utilized a stochastic meta-production frontier as this study does, their study considered heterogeneous technology defined by country. Thus, the study does not shed light on technology gaps within Ghana as the present study does.

In their study, Ofori-Bah and Asafu-Adjaye (2011) investigated the extent to which crop diversity on cocoa farms affects farmers' TE, and whether the production practice offers economies of scope from the sharing of farm inputs by crops on the same plots. Their results generated by applying the prototypical Stochastic Frontier (SF) to a sample of 340 cocoa farmers for the 2008/2009 growing season showed that diversified cocoa farms were more efficient than undiversified farms. Ofori-Bah and Asafu-Adjaye (2011) further showed that the former exhibited possibilities for cost complementarities between the production of cocoa and other crops on the same farm. Furthermore, Ofori-Bah and Asafu-Adjaye (2011) showed that shade, tree age, and full-time farming had significant effects on the TE of cocoa farmers. Besseah and Kim (2014) applied the prototypical SF to show that Ghanaian cocoa farmers for the 2005/2006 growing season were producing at only 48 percent of their productive potential. The main drivers of the TE of cocoa farmers put forth by Besseah and Kim (2014) were (1) farmer gender, age, and migratory status, (2) production equipment, and (3) location captured by regional dummies.

Unlike the studies discussed so far, Onumah et al. (2013) in their study utilized the stochastic meta-frontier framework to differentiate cocoa production in Ghana by organic and conventional practices. They showed that the conventional frontier was relatively close to the meta-frontier than that of the organic. Onumah et al. (2013) also showed that mean TE relative to the meta-frontier was 0.59 for the organic and 0.71 for the conventional system. Finally, Onumah et al. (2013) showed that farmers using organic practices could benefit from economies of scale since their RTS were 1.209 compared with 0.923 for conventional practices.

Contrary to its predecessors, the most recent study by Danso-Abbeam and Baiyegunhi (2019) used the stochastic meta-frontier framework to differentiate cocoa production technology along regional lines. Their results that reflected conditions for the 2015/2016 cocoa season indicated that cocoa farmers from the Western, Brong Ahafo, Ashanti, and Eastern regions do not meet their potential with mean TE estimated at 0.65, 0.76, 0.60, and 0.74, respectively. Danso-Abbeam and Baiyegunhi (2019) also showed that each region faces a technology gap when its performances are compared with the technology available in the industry. Danso-Abbeam and Baiyegunhi (2019) identified sources of farmers' technical inefficiency emanating from a combined effect of socioeconomic (education and experience) and farm-specific factors (farm asset, age of cocoa farm, and farm size).

Aside from the above TE-related literature, several studies have also shown that cocoa productivity ( $\mathrm{kg} / \mathrm{ha}$ ) in Ghana is mostly driven by technology (improved and hybrid varieties), labor use, nonlabor inputs use, land tenure, and biotic and abiotic stresses (Abenyega and Gockowski 2001; Teal, Zeitlin, and Maamah 2006; Vigneri 2007; Aneani and Ofori-Frimpong 2013; Tsiboe and Nalley 2016; Tsiboe et al. 2016, 2018a).

While the literature devoted to the TE of cocoa production in Ghana is limited in the possibility of heterogeneous technology, the analysis presented so far is confined to only one season. Currently, the TE of cocoa production in Ghana is known only for 2001/ 2002, 2005/2006, 2008/2009, and 2015/2016; values aside these seasons and annual changes thereof are unknown. Building on the previous studies, this article extends 
the literature by accommodating data from multiple seasons throughout Ghana to ascertain the spatiotemporal heterogeneity in Ghanaian cocoa production technology and efficiency. In doing so, the chronic nature of cocoa production technology gaps and technical inefficiency is ascertained.

\section{Study area and sample}

Among the then 10 administrative regions of Ghana, only six engage in cocoa production. ${ }^{2}$ These six regions (Ashanti, Brong Ahafo, Central, Eastern, Volta, and Western) are all located in the forest ecological zone of Ghana and are characterized by annual average temperatures between $24^{\circ} \mathrm{C}$ and $30^{\circ} \mathrm{C}$, and annual rainfall levels between 1,500 and 2,200 mm. These are conditions optimal for cocoa production (Wood and Lass 1987), thus making it possible for the cash crop to be grown in these regions. As shown in Figure 1, before the 1980s, the Ashanti region was the leading producer, followed by Brong Ahafo, Central, Western, and then the Volta region. Cocoa production in periods after the 1980s is dominated by the Western region, with its dominance continually increasing. Notwithstanding the similarity in climate across the six regions, they are characterized by major differences in infrastructure access and quality, and fertility status of soils, which could affect the productivity of cocoa. The sample used in this study captures production from all six regions.

The study's sample was compiled from (1) all seven rounds of the Ghana Living Standards Survey (GLSS) publicly available at the GSS National Data Archive (NADA); (2) all five rounds of the Ghana Cocoa Farmers Survey (GCFS) (Centre for the Study of African Economies (CSAE) 2016); (3) the first and second rounds of the Ghana Socioeconomic Panel Survey (GSPS) (Institute of Statistical Social and Economic Research (ISSER) and Economic Growth Center (EGC) 2016); (4) the base- and mid-line survey for the Cocoa Livelihood Program (CLP); (5) Tulane University's survey of child labor in cocoa-growing areas for 2008/2009 and 2013/2014; (6) a survey by The Royal Tropical Institute (KIT) (Tyszler, Bymolt, and Laven 2018). Detailed information on the sampling and data collection for all the surveys are published with each data. However, they all followed a two-stage stratified sampling design, where enumeration areas and households are selected in the first and second stages, respectively. Furthermore, except for the GCFS, GSPS, and CLP, where some households were repeated for multiple rounds, new households were sampled for the different rounds of the other surveys. The sample used in this study was limited to cocoa farmers with a yield above the 2.5th and below the 97.5th percentile by survey and region. Furthermore, farmers with farm sizes of less than 0.01 ha or greater than 50 ha were dropped from the analysis. Thus, the final sample consisted of 16,541 cocoa farmers. The data span across all six cocoa regions and 20 growing seasons from 1987/1988 to 2016/2017. Supplementary Table A1 gives a breakdown of the sample size by survey and season.

Supplementary Note A1 provides information on the construction of variables from each survey, and the summary statistics of variables used in this study are presented in Table 1. For the summary statistics, the combined sample was standardized by dividing each value by its respective survey-wave means to assess their trends over the forgoing period (1987-2017). Regional plots of the variables used in this study across all the surveys are presented in Figure 2.

\footnotetext{
${ }^{2}$ At the time of data collection, Ghana had 10 administrative regions. Currently, there are 15 administrative regions. Due to a lack of consistent geo-referencing variables across the different surveys used in this study, the old administrative regions demarcation is maintained
} 


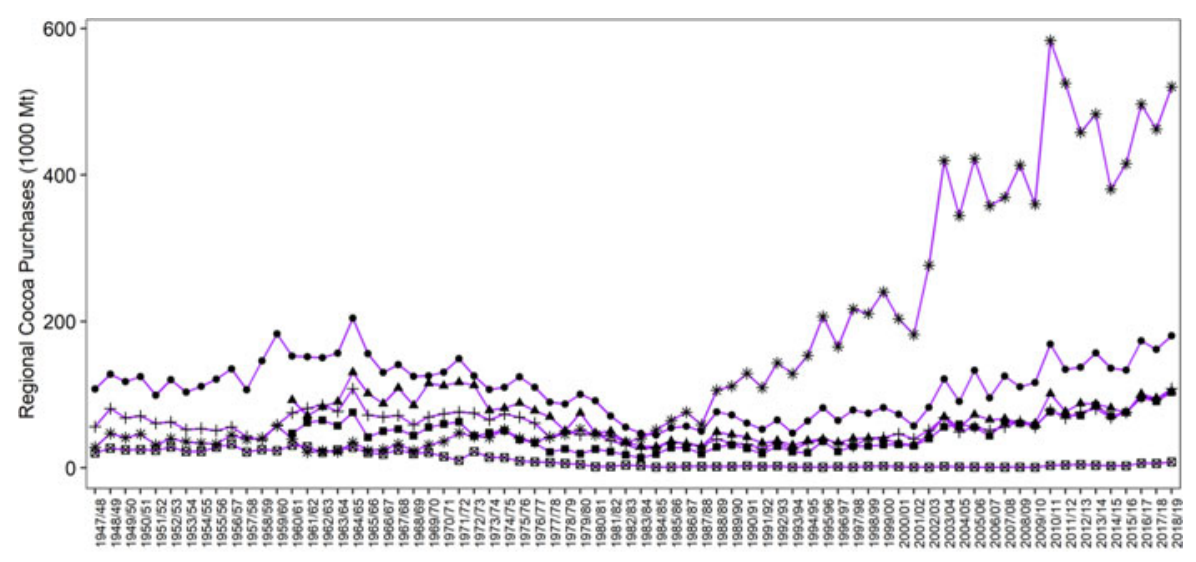

- Ashanti ^ Brong.Ahafo - Central + Eastern \& Volta * Western

Figure 1. Regional cocoa purchase in Ghana from 1947 to 2018. Constructed using data retrieved from the Ghana Cocoa Board website, https://cocobod.gh/weakly_ purchase.php.

Table 1 indicates that the farmers in the sample were on average about 48 years old, with 24 percent and 58 percent of them being females and educated, respectively. The cocoa farmers in the sample originated from households of about five members, with about 28 percent and 28 percent having access to credit and extension, respectively. In terms of regional variation, there are significant differences across all the farmer and household variables. Notable among these differences shown in Figure 2(a-f) are (1) female participation was the highest and the lowest in the Ashanti and Volta regions; (2) Western region farmers were the most likely to be educated while their peers in the Volta region were least likely; (3) Central and Ashanti region farmers were most and least likely to have credit access, respectively; and (4) farmers in the Eastern and Central regions were most and least likely to have access to extension. Table 1 indicates that over the forgoing period, the mean age of cocoa farmers, the probability of observing a female or educated cocoa farmer in Ghana, and access to extension have all significantly increased. On the contrary, the probability of observing a cocoa farmer in Ghana with access to credit significantly declined.

On the production side, the mean cocoa farm size over the forgoing period was estimated at 4.69 ha and has significantly increased by 0.64 percent annually. Cocoa farm size varied significantly $(\mathrm{p}<0.05)$ across the six regions, with the largest being in Brong Ahafo, followed by Western, Ashanti, Central, Eastern, and then Volta, respectively (Figure 2(g)). Mean cocoa yield over the forgoing period was estimated at $346 \mathrm{~kg} / \mathrm{ha}$. The largest mean yield over the sample was recorded for the Eastern region, followed by the Brong Ahafo, Ashanti, Western, Volta, and Central regions, respectively. On average, cocoa yields over the forgoing period significantly $(\mathrm{p}<0.05)$ increased by about 2.51 percent annually.

From Table 1, the mean usage rate for hired labor, fertilizer, and pesticide was estimated at $24.21 \mathrm{man}-\mathrm{day} / \mathrm{ha}, 65.53 \mathrm{~kg} / \mathrm{ha}$, and $15.38 \mathrm{~L} / \mathrm{ha}$, respectively. These mean input usage rates varied significantly across the six regions. Particularly, the highest and lowest usage rates for fertilizer and pesticide were recorded in Western and Volta, respectively (Figure $3(\mathrm{k}-\mathrm{l})$ ). Table 1 also shows that hired labor, fertilizer, and 
Table 1. Summary statistics of Ghanaian cocoa farmers and their production (1987-2017)

\begin{tabular}{|c|c|c|c|}
\hline Variable & $\begin{array}{l}\text { Mean (SD) for } \\
\text { raw data }\end{array}$ & $\begin{array}{c}\text { Mean (SD) for } \\
\text { standardized data }\end{array}$ & $\begin{array}{c}\text { Trend (\%) for } \\
\text { standardized data }\end{array}$ \\
\hline \multicolumn{4}{|l|}{ Farmer } \\
\hline Age (years) & 48.369 (13.715) & $3.418^{\dagger}(1.367)$ & $0.678^{\star \star \star \dagger}[0.038]$ \\
\hline $\begin{array}{l}\text { Female } \\
\text { (dummy) }\end{array}$ & $0.238(0.426)$ & - & $0.187^{\star \star \star \dagger}[0.051]$ \\
\hline $\begin{array}{l}\text { Educated } \\
\text { (dummy) }\end{array}$ & $0.576(0.494)$ & - & $0.728^{\star \star \star \dagger}[0.046]$ \\
\hline \multicolumn{4}{|l|}{ Household } \\
\hline Size (AE) & $5.260(2.825)$ & $1.826^{\dagger}(1.104)$ & $0.142^{\star \star \dagger}[0.065]$ \\
\hline $\begin{array}{l}\text { Credit } \\
\text { (dummy) }\end{array}$ & $0.283(0.451)$ & - & $-2.706^{\star \star \star}[0.071]$ \\
\hline $\begin{array}{l}\text { Extension } \\
\text { (dummy) }\end{array}$ & $0.276(0.447)$ & - & $0.540^{\star \star \star}[0.090]$ \\
\hline \multicolumn{4}{|l|}{ Production } \\
\hline Land (ha) & $4.687(5.557)$ & $0.995^{\dagger}(1.015)$ & $0.644^{\star \star \star \dagger}[0.089]$ \\
\hline Yield (kg/ha) & 346.409 (908.425) & $1.162^{\dagger}(1.066)$ & $2.505^{\star \star \star \dagger}[0.076]$ \\
\hline $\begin{array}{l}\text { Household } \\
\text { labor (AE) }\end{array}$ & $3.270(1.876)$ & $1.769^{\dagger}(1.081)$ & $0.189^{\star \star \star}{ }^{\dagger}[0.058]$ \\
\hline $\begin{array}{l}\text { Hired labor } \\
\text { (man-days/ha) }\end{array}$ & $24.211(123.577)$ & $0.497^{\dagger}(1.013)$ & $0.668^{\star \star \star}{ }^{\dagger}[0.116]$ \\
\hline $\begin{array}{l}\text { Fertilizer } \\
(\mathrm{kg} / \mathrm{ha})\end{array}$ & $65.534(457.285)$ & $0.378^{\dagger}(1.024)$ & $1.700^{\star \star \star}{ }^{\dagger}[0.089]$ \\
\hline Pesticide (L/ha) & $15.279(126.612)$ & $0.386^{\dagger}(1.010)$ & $2.160^{\star \star \star \dagger}[0.134]$ \\
\hline \multicolumn{4}{|c|}{ Cocoa tree age (ratio) } \\
\hline $0-4$ years & $0.114(0.195)$ & - & $3.971^{\star \star \star \dagger}[1.284]$ \\
\hline $5-9$ years & $0.210(0.297)$ & - & $0.547[1.034]$ \\
\hline 10-19 years & $0.348(0.364)$ & - & $-7.736^{\star \star \star}[0.795]$ \\
\hline Over 19 years & $0.328(0.385)$ & - & $5.763^{\star \star \star \dagger}[0.880]$ \\
\hline
\end{tabular}

Sample size $=16,541$.

Standardized data are the raw data divided by survey-specific means.

Significance levels: ${ }^{*} p<0.10,{ }^{* *} p<0.05,{ }^{* \star *} p<0.01$.

${ }^{\dagger}$ Significant $(p<0.05)$ variation across regions. The variations were determined via a linear regression for continuous variables and a probit model for dummies. A trend variable, and a fixed effect for the region, as well as their interactions were included in the estimation. See Supplementary Table A2 for the underlying regression results.

pesticide use significantly $(\mathrm{p}<0.05)$ increased by 0.67 percent, 1.70 percent, and 2.16 percent, respectively, annually.

Perennial crops evolve through four distinct periods in their life cycle. First is an early period of no yield, followed by a period of exponential growth in yield, a period of increasing yield at a decreasing rate, and finally, a period of declining yields. These four life cycle stages also apply to cocoa production, where traditionally yields after 25 years decline slowly (Lass 2001). Alternatively, peak yield could occur at 15-25 years 


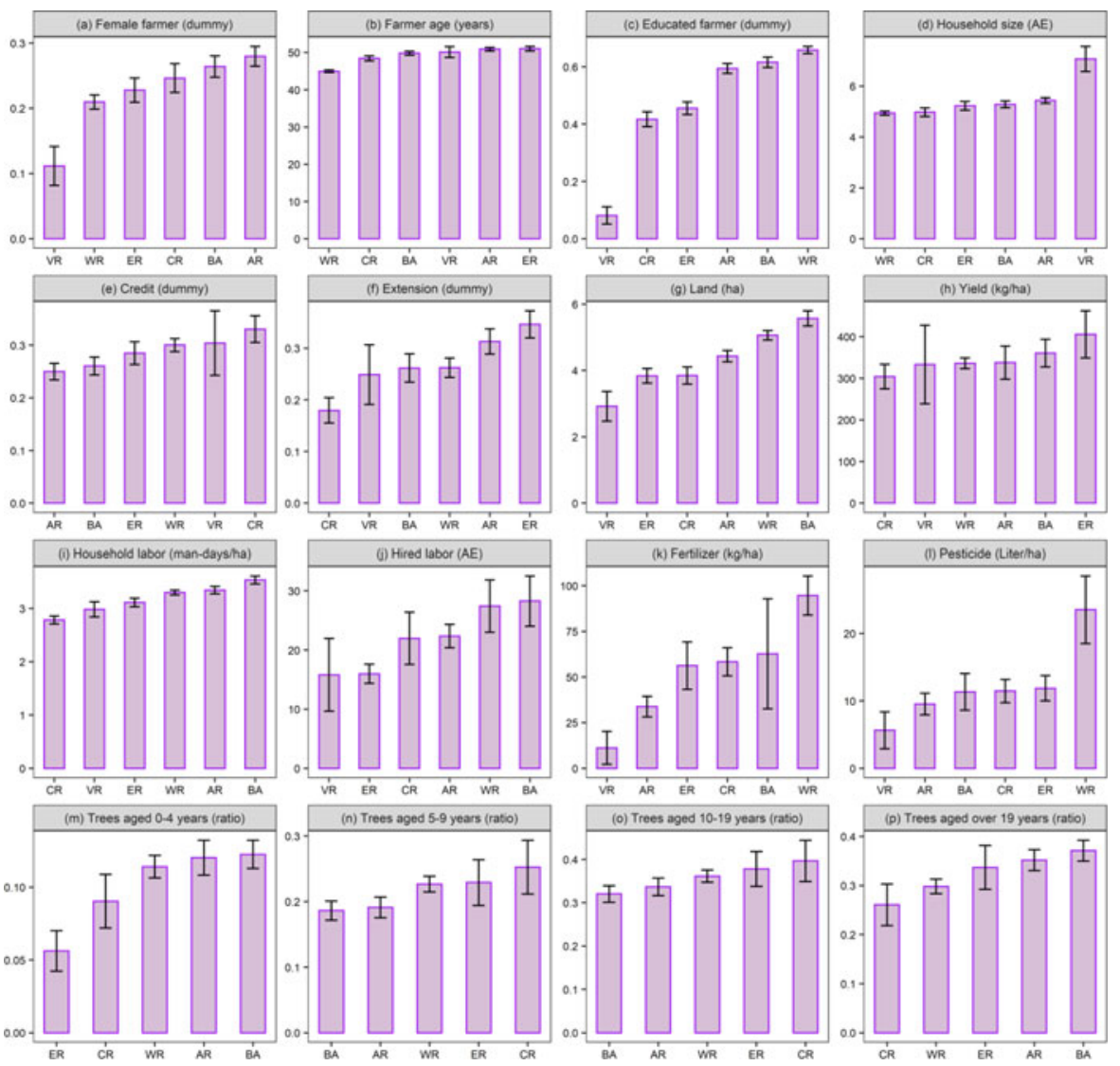

Figure 2. Regional variation in cocoa production yield/input and farmer demographics in Ghana (1987-2017). Constructed with 19 population-based surveys that represent 30 years of farmer-level data collection in Ghana over 20 growing seasons from 1987 to 2017. AR, Ashanti; BA, Brong Ahafo; CR, Central; ER, Eastern; VR, Volta; WR, Western.

after establishment with a profitable life of 50 years (Montgomery 1981). However, yields decline beyond 26 years. The aging of the capital stock of cocoa can confound the disentanglement of regional differences in cocoa production technology over time. This study dwells heavily on old survey data; thus, it is at the mercy of the information collected at the time the surveys were fielded. Only GLSS2, GLSS3, GCFS4, and GLSS5 had some information on tree age. Data from these four surveys shown in Table 1 indicate that from 2003 to 2010, Ghanaian cocoa farms on average had 11 percent, 21 percent, 35 percent, and 33 percent of their capital stock aged $0-4,5-9,10-19$, and over 19 years old, respectively.

The capital stock of cocoa for the average farm also varied significantly across regions, with the youngest (0-9 years) and oldest (over 19 years old) stocks found in the Central and Brong Ahafo regions, respectively (see Supplementary Table A3). The capital stock of cocoa aged 0-4 years and those over 19 years significantly increased annually by 3.97 percent and 5.76 percent, respectively. On the contrary, the tree stock aged 5-9 years remained unchanged, while the stock aged $0-4$ years declined by 7.74 


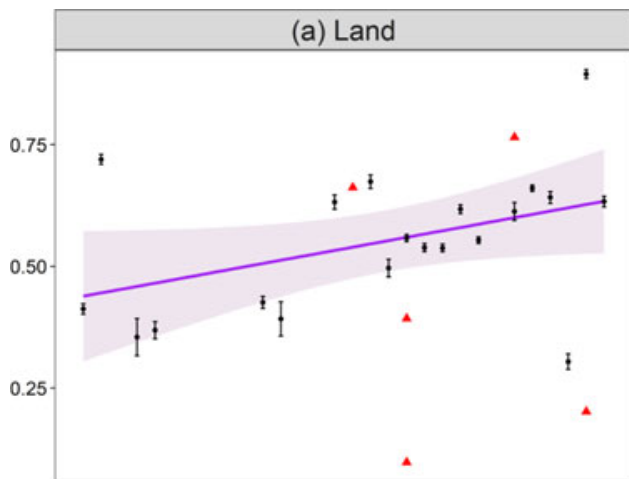

(d) Fertilizer

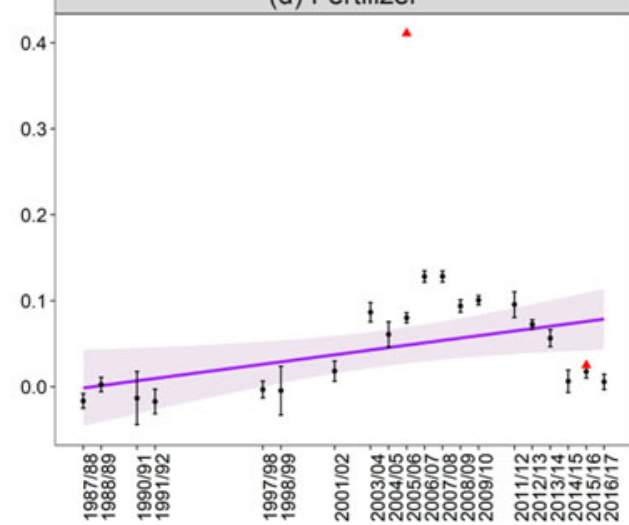

(b) Family labor

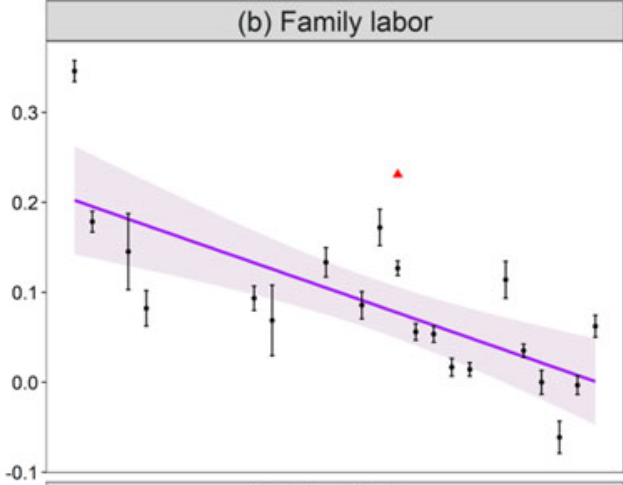

(e) Pesticide
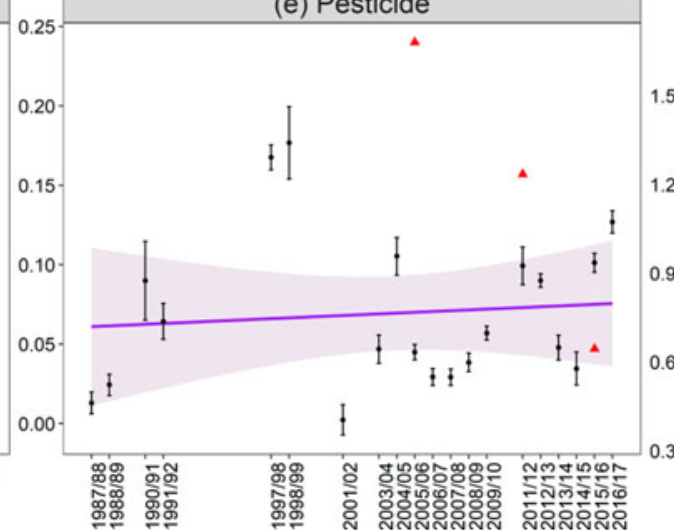

(c) Hired labor

$\Delta$

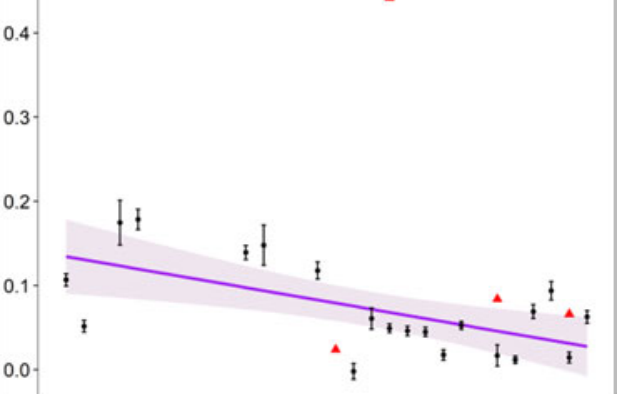

(f) Returns to scale

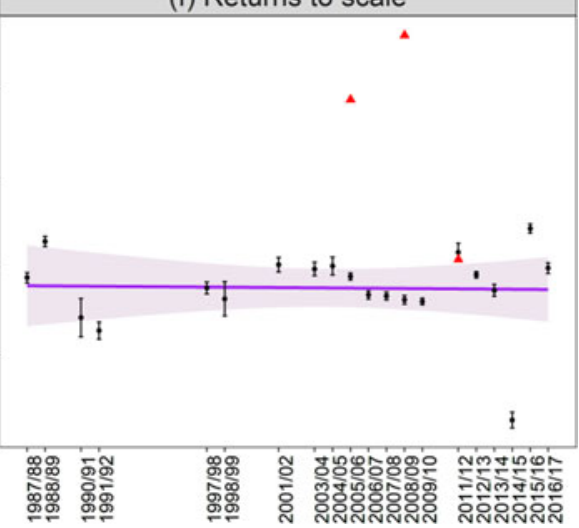

Figure 3. Cocoa meta-frontier elasticity trends in Ghana (1987-2017). Farmer-level elasticities were first estimated via a MSF analysis applied separately to 19 population-based surveys that represent 30 years of farmer-level data collection in Ghana over 20 growing seasons from 1987 to 2017 . The farmer-level elasticities were subsequently averaged across seasons. Each point on a subpanel represents the mean of the estimates and the length of its error bar represents its standard error. Points indicated by a filled triangle point-up are estimates from previous studies for the respective season. 
percent annually. These dynamics show that the average Ghanaian cocoa farm from 2003 to 2010 was aging, with much of the capital stock moving from a stage of increasing yield at an increasing rate to stages of yields increasing at decreasing rate or yields declining. Supplementary Table A3 also shows that the aging dynamics varied across regions with significant aging occurring among the stock in the Eastern region, followed by the Central, Western, Brong Ahafo, and then Ashanti regions, in that order.

\section{Methodology \\ Meta-frontier analysis theory}

Productive efficiency is the relationship between realized and feasible output, coupled with the assumption of optimized behavior of farmers, and subject to technology and price constraints. This relationship is further categorized into technical or allocative efficiency, with the two combining to form economic efficiency (Farrell 1957). Due to the unavailability of reliable data on input prices at the farmer level, this study focuses on TE, which deals with how well farmers manage inputs to attain potential yields. Empirically, TE is assessed either from the output or input perspective. From the output perspective, the observed output is compared with its potential given an input set; and under the input perspective, observed input levels are compared with their minimum required to produce a given output level. In terms of their operationalization, practitioners use models that are based either on the well-known Data Envelopment Analysis (DEA) (Charnes, Cooper, and Rhodes 1978, 1981) or on the Stochastic Frontier Analysis (SFA) (Aigner, Lovell, and Schmidt 1977; Meeusen and van Den Broeck 1977).

One major advantage of the prototypical DEA is that it imposes no functional form on the data; however, its frontier (i.e., the production function) is susceptible to outliers and measurement error, does not account for idiosyncratic shocks, and has no statistical properties for inferences. On the contrary, the SFA imposes a functional form on the data; however, its frontier (known as the SF) is less susceptible to outliers and measurement error and has statistical properties for inferences. Thus, because of its merits and the absence of reliable price information in the forgoing dataset, this study utilizes the output-oriented SFA approach.

Under the prototypical output-oriented SFA approach, farmers are assumed to utilize a homogeneous technology, coupled with best management practices, given an input set. Thus, depending on their input set, all farmers are expected to be operating at various points along the SF. Reasons for observing farmers below the SF can be attributed to technical inefficiency and/or idiosyncratic shocks. However, some farmers are also observed above the SF purely due to the latter. Under this framework, the prototypical SF is

$$
y_{i}=f\left(x_{i}\right) e^{v_{i}-u_{i}}
$$

where $y_{i}$ is the total production output by the $i$ th farmer. The function $f(\cdot)$ captures the relationship between the production inputs $\left(x_{i}\right)$ used in producing $y_{i}$. The terms $u_{i}$ and $v_{i}$ describe the deviation of the $i$ th farmer's production output from the production frontier that is attributable to technical inefficiency and idiosyncratic shocks, respectively.

The SFA approach is motivated by the distributional assumptions of $u_{i}$ and $v_{i}$ (Farrell 1957). Based on its negative skewness, $u_{i}$ is assumed to follow either half-normal, exponential, and truncated, or gamma distribution. However, due to 
computational difficulties (i.e., nonconvergence), this study assumes that $u_{i}$ follows a half-normal distribution with mean 0 and variance $\sigma_{u}^{2}\left[u_{i} \sim N^{+}\left(0, \sigma_{u}^{2}\right)\right]$. The deviation term, $v_{i}$, on the other hand, is assumed to follow a normal distribution with zero mean and variance $\sigma_{v}^{2}\left[v_{i} \sim N\left(0, \sigma_{v}^{2}\right)\right]$ (Belotti et al. 2013).

A superior and flexible model will allow for production variation $\left(u_{i}\right.$ and $\left.v_{i}\right)$ to be heteroscedastic. Thus, the variance of technical inefficiency is modeled as $\sigma_{u_{i}}^{2}=\exp \left(w_{i} \alpha\right)$, where $w_{i}$ contains covariates that affect technical inefficiency. The variance of the idiosyncratic shocks is also assumed to be heteroscedastic with an exponential functional form $\left[\sigma_{v_{i}}^{2}=\exp \left(z_{i}, \vartheta\right)\right]$, where $z_{i}$ and $\vartheta$ are vectors of determinants and parameters, respectively (Just and Pope 1979; Battese, Rambaldi, and Wan 1997). The superior and flexible model is represented as

$$
y_{i}=f\left(x_{i}\right) e^{v_{i}-u_{i}}, \quad u_{i} \sim N^{+}\left[0, \exp \left(w_{i} \alpha\right)\right], \quad v_{i} \sim N\left[0, \exp \left(z_{i}, \vartheta\right)\right]
$$

The TE score of the $i$ th farmer is calculated as

$$
\mathrm{TE}_{i}=y_{i}\left[f\left(x_{i}\right) e^{v_{i}}\right]^{-1}=e^{-u_{i}}
$$

The main objective of this article is to ascertain the spatiotemporal heterogeneity in Ghanaian cocoa production technology and efficiency. Thus, there is the need to formulate the prototypical SF in a way that captures how cocoa farmers in different regions of Ghana adopt distinct cocoa production technologies based on their specific circumstances. These circumstances include, but are not limited to, resource availability, government regulation, input price, and the environment. Since its introduction by Hayami (1969) and further developments by Hayami and Ruttan (1970, 1971), the meta-production frontier has been used by several empirical studies to capture the specific production technology adopting behavior of subgroups of farmer populations.

The literature initially proposed a mixed approach with a two-step procedure where the SF is estimated for the different groups in the first step and then a nonparametric method is utilized to determine the meta-frontier in the second step (Battese, Rao, and O'Donnell 2004; O’Donnell, Rao, and Battese 2008). Huang et al. (2014) indicated that the meta-frontier from the two-step mixed approach lacks statistical properties because it is deterministic. According to Huang et al. (2014), this is particularly problematic since it does not fully reflect the decision-making environment of farmers and fails to account for idiosyncratic shocks. Consequently, Huang et al. (2014) proposed a new two-step approach based on the core idea behind the prototypical SF and has desirable statistical properties that enable inference.

Under Huang et al. (2014)'s approach, the SF represented by equation (2) is first estimated separately for each farmer group (e.g., by regions), and then in the second step, the predicted output levels from the group-specific SFs are used as the observation for a pooled SF that captures all groups to estimate a meta-stochastic frontier (MSF). The second step directly estimates technology gaps by treating them as a conventional onesided error term $\left(u_{i}^{M}\right)$. The meta-frontier that envelops all region-specific frontiers $\left[f^{r}\left(x_{i}\right)\right]$ is represented as

$$
f^{r}\left(x_{i}\right)=f^{M}\left(x_{i}\right) e^{-u_{i}^{M}}, \quad u_{i}^{M} \sim N^{+}\left(0, \exp \left(w_{i} \alpha\right)\right)
$$


where $u_{i}^{M}>0$; therefore, $f^{r}\left(x_{i}\right) \leq f^{M}\left(x_{i}\right)$, and the ratio of region $r^{\prime}$ s frontier to the metafrontier is the technology gap ratio (TGR) represented as

$$
\mathrm{TGR}_{i}=f^{r}\left(x_{i}\right)\left[f^{M}\left(x_{i}\right)\right]^{-1}=e^{-u_{i}^{M}} \leq 1
$$

The TGR depends on the accessibility and extent of adoption of the available MSF, which, in turn, depends on farmers' specific circumstances, such as resource availability, government regulation, input price, and the environment. Given an input set, each farmer's output relative to the MSF-i.e., their meta-frontier technical efficiency (MTE) - is represented as

$$
\operatorname{MTE}_{i}=f^{r}\left(x_{i}\right)\left[f^{M}\left(x_{i}\right) e^{v_{i}}\right]^{-1}=\mathrm{TGR}_{i} \times \mathrm{TE}_{i} .
$$

\section{Empirical model}

For the empirical analysis, production information from the various surveys is likely to be incomparable because of differences in respondents, interview modes, survey contexts, sampling designs, and survey questions. Thus, it will be naive to take the value from the various surveys at face value and then harmonize them as one dataset, without considering the sources of incomparabilities. To address this issue, the study utilized a two-step research design.

For the first step of the research design, the meta-stochastic frontier analysis was estimated separately for each survey wave. By estimating survey-wave-specific metastochastic frontiers, the study relaxes the assumption that the production frontier remains unchanged as does the relationship between factors that are associated with technical inefficiency. The functional form $f_{t}(\cdot)$ used by previous studies estimating cocoa SFs for Ghana was either the Translog or Cobb-Douglas. However, this study preferred the Translog because of its relative flexibility; since Cobb-Douglas functional form is a special case of the Translog, this permits testing for the former.

The stylized empirical model used in this study is

$$
\begin{aligned}
& \ln y_{i r t}= \beta_{0 r}+\sum_{j} \beta_{j r} \ln x_{j i r t}+\frac{1}{2} \sum_{j} \sum_{k} \beta_{j k r} \ln x_{j i r t} \ln x_{k i r t}+\frac{1}{2} \sum_{j} \sum_{s} \beta_{j s r} \ln x_{j i r t} \tilde{x}_{s i r t} \\
&+\sum_{j} \beta_{j r} \tilde{x}_{j i r t}+\frac{1}{2} \sum_{j} \sum_{k} \beta_{j k r} \tilde{x}_{j i r t} \tilde{x}_{k i r t}+\frac{1}{2} \sum_{j} \sum_{s} \beta_{j s r} \tilde{x}_{j i r t} \ln x_{s i r t}+v_{i r t}-u_{i r t} \\
& \tilde{x}_{j i r t}=\operatorname{arcsinh}\left[x_{j i r t}\right], \quad u_{i r t} \sim N^{+}\left[0, \exp \left(w_{i r t} \alpha\right)\right], \quad v_{i r t} \sim N\left[0, \exp \left(z_{i r t}, \vartheta\right)\right] .
\end{aligned}
$$

The total cocoa output for the ith farmer in region $r$ for the $t$ season was taken as the outcome variable $\left(y_{i r t}\right)$, and the inputs $\left(x_{j i r t}\right)$ included the total amounts of land, family, and hired labor, fertilizer, and pesticide. In terms of production variance drivers, the vector for the inefficiency function $\left(w_{i}\right)$ contained covariates that control for farmer characteristics (gender, age, and education) and access to credit and extension.

It is worth noting that farmer-level data for developing countries do not come without shortcomings. Particularly, only a handful of farmers report nonzero values for nonland production inputs. The study faced a comparable situation. Consequently, in order not to lose observation due to zeros reported for at least one nonland input, the log function was replaced with an inverse hyperbolic sine function $\left(\tilde{x}_{j i r t}=\operatorname{arcsinh}\left[x_{j i r t}\right]\right)$ for such inputs 
(Bellemare and Wichman 2020). The outcome and the input variables were also normalized by dividing each observation by its survey-specific mean.

For each survey wave, parameters of the regional- and overall meta-frontier were obtained via maximum-likelihood estimation, utilizing the "frontier" command in Stata 16.1. Given the maximum-likelihood parameters, farmer-level elasticities for each input were estimated as the first derivative $f_{t}(\cdot)$ with respect to that input and evaluated at every observation. The elasticity for the inputs without and with zeroes is given by $\in_{j i r t}=\beta_{j r}+\sum_{k} \beta_{j k r} \ln x_{k i r t}+\sum_{s} \beta_{j s r} \tilde{x}_{s i r t}$ and $\in_{j i r t}=\left(\beta_{j r}+\sum_{k} \beta_{j k r} \ln x_{k i r t}+\sum_{s} \beta_{j s r} \tilde{x}_{\text {sirt }}\right) \cdot\left(x_{j i r t} / \sqrt{x_{j i r t}^{2}+1}\right)$, respectively. Consequently, farmer-level production RTS were estimated as the summation of all the input elasticities. Given the estimated frontiers, each farmer's TE relative to the regional SF (TE) and MSF (MTE) and their technology gap ratio (TGR) were estimated as outlined in equations (3), (5), and (6).

Since the farmer-level elasticities and scores (TGR, TE, and MTE) are all unitless, the second step of the research design pools them across all surveys into one sample to assess their spatiotemporal heterogeneity. To that end, the regression framework in equation (8) was utilized.

$$
\tau_{h}=\theta_{0}+\theta_{s} S_{h}+\theta_{r} R_{h}+\vartheta_{h}
$$

In equation (8), $\tau_{h}$ is the elasticities/score of interest for household $h ; S_{h}$ and $R_{h}$ are categorical variables for six regions and 20 seasons, respectively. For the case of elasticities and RTS, equation (8) was estimated as a linear regression model. However, since the range of the scores (TGR, TE, and MTE) is $[0,1]$, a fractional regression model was utilized for them.

By omitting the category Ashanti $(r=1)$ and 198719/88 $(s=1)$ for region and season, respectively, the parameter $\theta_{0}$ serves as the average elasticity/score for the Ashanti region during the 1987/1988 growing season, ceteris paribus. Consequently, the marginal changes in elasticities/scores for a given region-season combination, $\{r, s\} \neq\{1,1\}$, over the omitted categories, is equal to their respective parameters in vectors $\boldsymbol{\theta}_{\boldsymbol{s}}$ and $\boldsymbol{\theta}_{\boldsymbol{r}}$. Furthermore, the mean of the elasticities/scores for a given region/season was taken as the mean of the seasonal/regional estimates for that region/season. The resulting region-specific elasticities/scores from Equation (8) were plotted on regional maps to show their spatial heterogeneity, and the seasonal-specific elasticities/scores were plotted on a scatterplot to show their temporal dynamics.

\section{Results and discussions}

The study deliberates in detail the spatiotemporal dynamics of the production function parameters, technology gaps, and TE among Ghanaian cocoa farmers, and provides alternative policy targeting. On the contrary, in the interest of space, discussions on the covariates in the production inefficiency function are omitted, as they are extensively deliberated in previous studies (Binam, Gockowski, and Nkamleu 2008; Ofori-Bah and Asafu-Adjaye 2011; Onumah et al. 2013; Besseah and Kim 2014; Danso-Abbeam and Baiyegunhi 2019). For the first stage of the research design, 126 stochastic frontier models were estimated across surveys and regions; thus, in order not to litter the paper with tables, the maximum-likelihood estimates of the Translog production output function $\left[f^{r}\left(x_{i t}\right)\right]$ and estimates for the inefficiency function $\left[w_{i r t} \alpha\right]$ 
from these models are omitted. ${ }^{3}$ The rejection rates of critical model diagnostic tests and sources of variability for the 126 models are shown in Table 2. Production elasticities for the regional- and meta-frontiers are shown in Table 3, and plots of the temporal dynamics of the elasticities are shown in Figure 3. Cocoa production technology level and TE by region and season are shown in Figures 4 and 5, respectively.

\section{Model specification tests}

First, the Cobb-Douglas functional form for the production function was evaluated by imposing restrictions on the Translog functional form (i.e., the cross terms are jointly equal to zero). The Cobb-Douglas restriction was rejected at a very low rate (averaged about 13 percent). This low rate implied that the fit from the Translog functional is like that of the Cobb-Douglas. However, based on literature consensus (Binam, Gockowski, and Nkamleu 2008; Ofori-Bah and Asafu-Adjaye 2011; Onumah et al. 2013; Danso-Abbeam and Baiyegunhi 2019) and the two-step research design employed to overcome any potential survey bias, the use of the Translog was maintained.

Central to the MSF approach is the negatively skewed error specification indicating technical inefficiency. Failure to reject the null hypothesis of a nonnegatively skewed error can be taken as justification to estimate the models by ordinary least squares (OLS). The study, therefore, performed three tests to verify the error specification required for the MSF approach. These included two skewness tests of the residuals resulting from an OLS estimation (Schmidt and Lin 1984; Coelli 1995), and a one-sided generalized likelihood-ratio test for technical inefficiency (Gutierrez, Carter, and Drukker 2001). The two types of tests were rejected at varying rates (20-72 percent) but indicated that the negative skewed error needed for the estimation of the models via the SFA was met. Despite the significant variation in these tests, there exist a host of studies that indicates various levels of technical inefficiency and technology in Ghanaian cocoa production (Binam, Gockowski, and Nkamleu 2008; Ofori-Bah and Asafu-Adjaye 2011; Onumah et al. 2013; Besseah and Kim 2014; Danso-Abbeam and Baiyegunhi 2019); thus, the study proceeds with the MSF.

The null hypotheses that technical inefficiency is not influenced by the variables in the inefficiency function (i.e., $H_{\mathrm{o}}: \alpha=0$ ) also had varying rejection rates (24-61 percent) that generally provided further statistical justification for the heteroskedastic technical inefficiency function. Furthermore, for each of the 19 surveys, the likelihood-ratio test for the null hypothesis that the regional cocoa production frontiers are similar was rejected at a rate of 90 percent, and thus, supports the fact that cocoa farmers in Ghana operate under heterogeneous technologies along regional lines. ${ }^{4}$ The conclusion reflects that of Danso-Abbeam and Baiyegunhi (2019).

Table 2 indicates that the mean of the proportion of cocoa production variance due to technical inefficiency $\left[\gamma=\sigma_{u}^{2} / \sigma^{2}\right]$ across the models ranged from 0.43 to 0.67 . Since these ratios are above if not close to 0.5 , they suggest that a considerable amount of the observed variation in cocoa output could be attributed to the inefficient use of inputs.

\footnotetext{
${ }^{3}$ All results can be generated using replication materials available at https://github.com/ftsiboe/ Agricultural-Productivity-in-Ghana.

${ }^{4}$ For the likelihood ratio test, the restricted log-likelihood value is from the national-frontier, and that for the unrestricted is the sum of the regional-frontier log-likelihood values. The test was done separately for each survey-wave.
} 
Table 2. Rejection rates of hypothesis tests and sources of variability for regional- and meta-frontier models for cocoa production in Ghana (1987-2017)

\begin{tabular}{|c|c|c|c|c|c|c|c|}
\hline \multirow[b]{2}{*}{ Test/statistic } & \multicolumn{5}{|c|}{ Ecology production frontier } & \multirow[b]{2}{*}{ National-frontier } & \multirow[b]{2}{*}{ Meta-frontie } \\
\hline & Ashanti & $\begin{array}{l}\text { Brong } \\
\text { Ahafo }\end{array}$ & Central & Eastern & Western & & \\
\hline \multicolumn{8}{|c|}{ Rejection rates of hypothesis tests (\%) } \\
\hline$C D$ test & 9.81 & 16.41 & 17.35 & 19.58 & 13.01 & 16.92 & 0.04 \\
\hline Schmidt and Lin (1984) ${ }^{a}$ & 43.89 & 56.83 & 52.79 & 46.27 & 23.24 & 23.29 & 26.00 \\
\hline $\begin{array}{l}\text { Gutierrez, Carter, and Drukker } \\
(2001)^{\mathrm{a}}\end{array}$ & 38.92 & 49.55 & 48.47 & 38.65 & 19.94 & 22.19 & 23.62 \\
\hline Inefficiency function test & 45.17 & 45.44 & 35.99 & 60.50 & 30.75 & 32.55 & 23.98 \\
\hline \multicolumn{8}{|l|}{ Sources of variability ${ }^{b}$} \\
\hline Gamma $\left[\gamma=\sigma_{u}^{2} / \sigma^{2}\right]$ & $0.54[0.10]$ & $0.43[0.11]$ & $0.46[0.12]$ & $0.50[0.10]$ & $0.67[0.08]$ & $0.59[0.08]$ & $0.66[0.09]$ \\
\hline
\end{tabular}

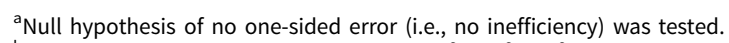

${ }^{\mathrm{b}}$ Inefficiency variance $\left[\sigma_{u}\right]$, total variance $\left[\sigma^{2}=\sigma_{u}^{2}+\sigma_{v}^{2}\right]$; values in brackets are standard errors. 
Table 3. Regional- and meta-frontier elasticities for cocoa production in Ghana (1987-2017)

\begin{tabular}{|c|c|c|c|c|c|c|c|}
\hline Elasticity & \multicolumn{6}{|c|}{ Regional production frontier } & Meta-frontier \\
\hline Land & $0.501^{\star \star \star}(0.101)$ & $0.681^{\star \star \star}(0.115)$ & $0.663^{\star \star \star}(0.154)$ & $0.970^{\star \star \star}(0.133)$ & $0.737^{\star \star}(0.291)$ & $0.589^{\star \star \star}(0.077)$ & $0.591^{\star \star \star}(0.001)$ \\
\hline Family labor & $-0.004(0.037)$ & $0.093^{\star \star}(0.042)$ & $0.085(0.055)$ & $0.395^{\star \star \star}(0.049)$ & $0.205^{\star}(0.106)$ & $0.132^{\star \star \star}(0.028)$ & $0.073^{\star \star \star}(0.001)$ \\
\hline Hired labor & $0.041(0.047)$ & $0.095^{\star}(0.053)$ & $-0.008(0.070)$ & $0.075(0.062)$ & $0.092(0.133)$ & $0.143^{\star \star \star}(0.036)$ & $0.052^{\star \star \star}(0.001)$ \\
\hline Fertilizer & $0.044(0.053)$ & $0.011(0.061)$ & $0.031(0.080)$ & $-0.190^{\star \star \star}(0.070)$ & $-0.005(0.153)$ & $0.063(0.041)$ & $0.065^{\star \star \star}(0.001)$ \\
\hline Returns to scale ${ }^{a}$ & $0.631^{\star \star \star}(0.098)$ & $0.933^{\star \star \star}(0.113)$ & $0.828^{\star \star \star}(0.147)$ & $1.157^{\star \star \star}(0.129)$ & $1.022^{\star \star \star}(0.282)$ & $1.039^{\star \star \star}(0.075)$ & $0.844^{\star \star \star}(0.002)$ \\
\hline
\end{tabular}

Significance levels: ${ }^{*} p<0.10,{ }^{* *} p<0.05,{ }^{* \star *} p<0.01$.

${ }^{a}$ Null hypothesis of constant RTS was tested. 


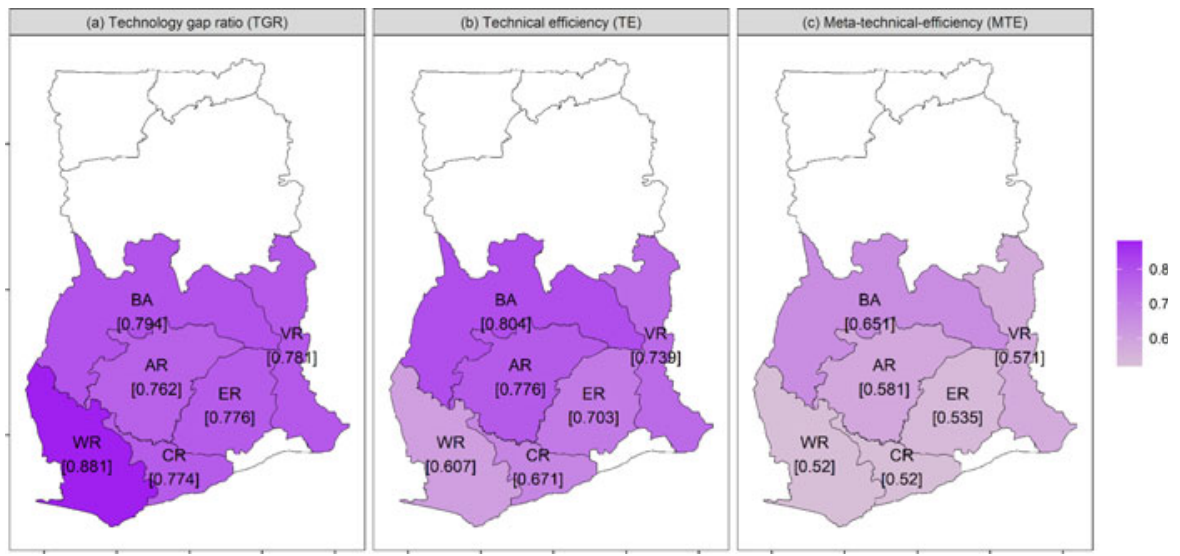

Figure 4. Regional variation in cocoa production technology and TE in Ghana (1987-2017). Farmer-level TGR, TE, and MTG were first estimated via a MSF analysis applied separately to 19 population-based surveys that represent 30 years of farmer-level data collection in Ghana over 20 growing seasons from 1987 to 2017. The farmerlevel estimates were subsequently averaged across regions. AR, Ashanti; BA, Brong Ahafo; CR, Central; ER, Eastern; VR, Volta; WR, Western.

The remaining variation could be attributed to idiosyncrasies such as biotic and abiotic shocks, statistical errors in data measurement, and the model specification. Previous studies on cocoa in Ghana estimated the proportion of cocoa production variance due to technical inefficiency to be 0.75 (Binam, Gockowski, and Nkamleu 2008), 0.99 (Ofori-Bah and Asafu-Adjaye 2011), and 0.60 (Besseah and Kim 2014). Along regional lines, Danso-Abbeam and Baiyegunhi (2019) estimated $\gamma$ to be $0.59,0.41$, 0.89 , and 0.94 for the Western, Brong Ahafo, Ashanti, and Eastern regions, respectively. In this study, the mean of the estimated $\gamma$ for the meta-frontier across all the models was 0.66, implying that a considerable amount of the observed variation in cocoa output, given the regional frontiers, could be attributed to technological gaps.

\section{Output elasticities with respect to inputs}

The production elasticities by region and season are shown in Table 3 and Figure 3, respectively. Across the models and where statistically significant at $\mathrm{p}<0.10$, the output elasticities for land, family labor, hired labor, fertilizer, and pesticide are all positive for both the regional- and meta-frontiers. The only exception is fertilizer in the Eastern region. The greatest contributor to cocoa production is land, with an estimated elasticity ranging from 0.50 to 0.97 in the Ashanti and Eastern regions, respectively. These estimates show the crucial role played by land in increasing Ghanaian cocoa productivity and resonate with the results of the previous studies analyzing cocoa in Ghana (Binam, Gockowski, and Nkamleu 2008; Ofori-Bah and Asafu-Adjaye 2011; Onumah et al. 2013; Besseah and Kim 2014; Danso-Abbeam and Baiyegunhi 2019). The seasonal estimates of the land elasticity for the meta-frontier presented in Figures 3(a) show a consistent and steady increase over the forgoing period. Cocoa farming is inherently labor-intensive; thus, it is not surprising that land is followed by family labor ( -0.004 to 0.395 in Ashanti and Eastern) and then by hired labor ( -0.008 to 0.143 

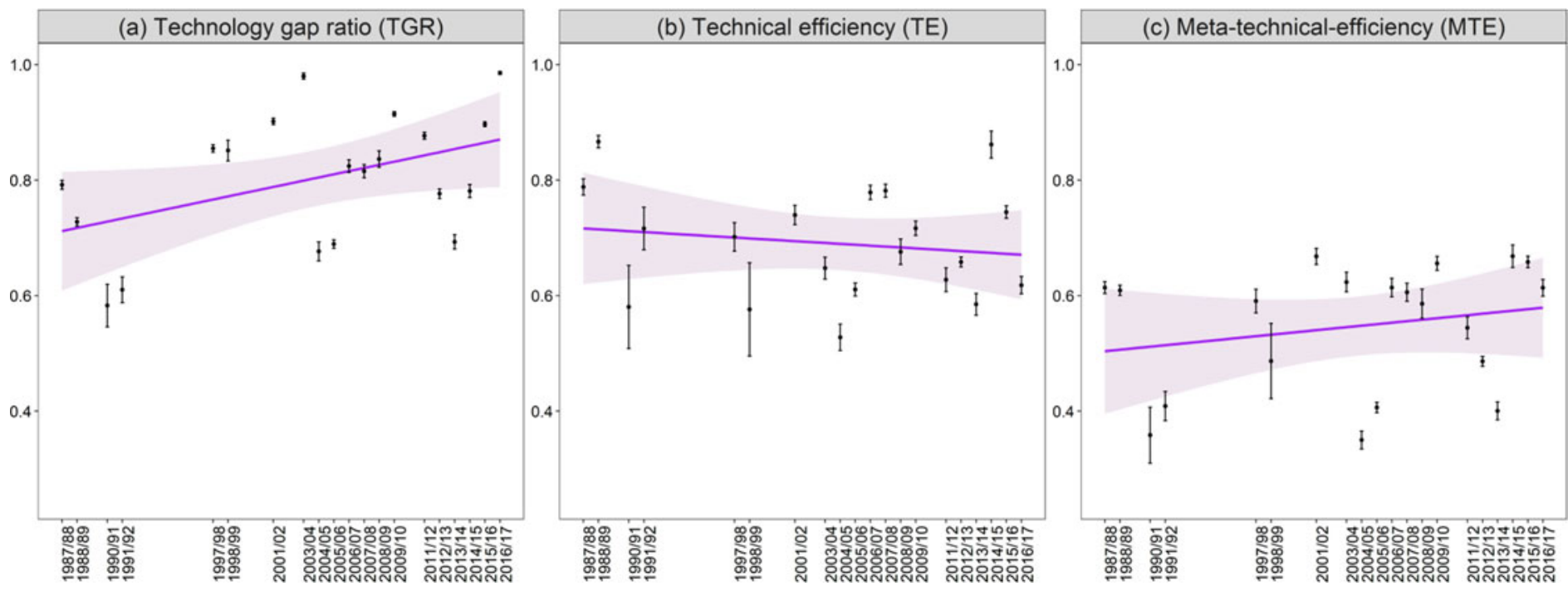

Figure 5. Cocoa production technology level and TE trends in Ghana (1987-2017). Farmer-level TGR, TE, and MTG were first estimated via a MSF analysis applied separately to 19 population-based surveys that represent 30 years of farmer-level data collection in Ghana over 20 growing seasons from 1987 to 2017 . The farmer-level estimates were subsequently averaged across seasons. Each point on a subpanel represents the mean of the estimates and the length of its error bar represents its standard error. Points indicated by a filled triangle point-up are estimates from previous studies for the respective season. 
in Central and Western). Contrary to land, the responsiveness of cocoa production to both family and hired labor has declined over the same period.

In their study partly covering cocoa labor use dynamics within the producing households in Ghana, Tsiboe et al. (2018a,b) showed that the responsiveness of cocoa to household and nonhousehold labor was 0.053 and 0.039 , respectively. However, when disaggregated, the labor elasticities were estimated at $0.013,0.015$, and 0.005 for adult male, adult female, and child labor, respectively. Thus, given the host of policies implemented to reduce child labor in cocoa production, it is not surprising that the study observed a decline in labor elasticities. Another reason that is discussed below is that aging capital stock could diminish returns to labor.

Labor is followed by pesticide with an estimated elasticity ranging from 0.03 to 0.08 in the Central and Eastern regions, respectively. Pesticide is followed by fertilizer with an estimated elasticity ranging from -0.19 to 0.06 in the Eastern and Western regions, respectively. Since fertilizer improves soil quality, and pesticides kill pests that potentially cause yield losses in cocoa, the prior expectation was that their associated elasticities will all be positive. However, fertilizer elasticity among Eastern region cocoa farmers was negative. According to the literature, a negative sign for the elasticity for such inputs could be attributed to the fact that Ghanaian cocoa farmers use input brands that are unapproved by COCOBOD and also inappropriately apply inputs (Denkyirah et al. 2016). Consequently, the negative elasticity for fertilizer paints a picture that suggests that this may be at play in the Eastern region.

The differences in the output elasticities for the inputs for the region-specific production frontiers imply that cocoa production structure and technology is regionally not homogeneous. Figure 3(d) shows that fertilizer elasticity for the meta-frontier was constant for 1987-1998, improved for 1998-2008, and steadily declined for 2008-2017. For pesticides, a sharp improvement and decline are observed for 19871998 and 1987-2005, respectively, and a steady improvement is seen for 2006-2017. The temporal dynamics of the elasticities for labor, fertilizer, and pesticide paints a picture that suggests that GoG-led CODAPEC and HI-TECH policies followed two different unique pathways of influencing cocoa production.

\section{Returns to scale}

According to the literature, as an important technological and economic characteristic of the production structure, RTS have implications for the transformational patterns of agricultural and distributional effects of agricultural policies (Takeshima, Houssou, and Diao 2018). Previous studies have shown mixed results concerning household cocoa production RTS in Ghana. Ofori-Bah and Asafu-Adjaye (2011) estimated a value of 1.68, implying an increasing RTS technology in 2008/2009, and Besseah and Kim (2014) estimated a value of 1.04, implying a constant RTS technology in 2005/2006. On the contrary, derived from the presented results, the regional RTS for Danso-Abbeam and Baiyegunhi (2019) ranged from 0.42 to 0.81 for cocoa production in the Ashanti and Western regions, respectively. Consequently, the derived RTS from Danso-Abbeam and Baiyegunhi (2019) suggest that cocoa production in Ghana for the 2015/2016 season was characterized by decreasing RTS technology. In this study, the RTS for the Eastern, Volta, and Western regions were all greater than unity, implying an increasing RTS technology. On the contrary, those for Ashanti, Brong Ahafo, and Central were less than unity, implying a decreasing RTS technology. Figure 3(f) shows that the RTS for cocoa 
over the forgoing period have remained constant at the decreasing RTS levels. While a constant RTS technology is desirable, remaining at the decreasing RTS level is problematic since it will imply that long-run average costs are increasing, an indication of diseconomies of scale (Truett and Truett 1990). Thus, there is a need to identify the factors associated with the constant low level of RTS to curtail them via appropriate policies.

\section{Technology gap}

The plots of the seasonal and regional TGR, a measure of technology use concentration, are presented in Figures 4(a) and 5(a). The possible values of the TGR are $[0,1]$, where values closer to one indicate that the respective regional-frontier is tangent to the meta-frontier. Closeness to one further implies that there is no room for technological improvement given what is already available in the country. On average, the mean TGR was 0.79 , indicating that cocoa farmers in Ghana were faced with a technology gap of about 0.21 percent from 1987 to 2017 . At the regional level, Figure 4(a) shows that the best cocoa production technology was in the Western region with the TGR estimated at 0.88, followed by Brong Ahafo (0.79), Volta (0.78), Eastern (0.77), Central (0.77), and then Ashanti (0.76). From the smallest to the largest, these values translate to technological gaps of about 12 percent, 21 percent, 22 percent, 23 percent, 23 percent, and 24 percent, respectively. Furthermore, the null hypothesis that the regional technological gaps are equal to zero was soundly rejected at $\mathrm{p}<0.05$. This supports the initial assertion that cocoa production structure and technology is regionally not homogeneous. Compared with Danso-Abbeam and Baiyegunhi (2019), this study's estimates of the TGR were higher for the Ashanti and Western regions and lower for the Brong Ahafo and Eastern regions.

Figure 5(a) also shows that the TGR increased steadily from 1987 to 2017. Like Vigneri (2007), the improvement in the TGR after 2002 could partly be linked to the HI-TECH and CODAPEC programs. Even though the government is committed to CODAPEC, the scale of HI-TECH has dwindled because of poor farmer repayment of credited fertilizer (Vigneri 2007; Kolavalli and Vigneri 2011, 2017). At the time of this study, COCOBOD supplied a limited quantity of subsidized fertilizers via LBCs for all cocoa farmers. These changes could lead to a depletion of the TGR improvements.

\section{Technical efficiency}

The results for the TE scores relative to the regional frontiers are presented in Figures 4 (b) and 5(b). Values closer to one indicate a higher level of TE. The estimated values showed that the mean TE is 0.72 ; thus, cocoa farmers operated at 72 percent of the potential possible in their respective regions. This study's estimated mean TE (0.72) is higher than that of Binam et al. (2008) (0.44), Ofori-Bah and Asafu-Adjaye (2011) (0.48), Besseah and Kim (2014) (0.47), and Danso-Abbeam and Baiyegunhi (2019) (0.69). Another interesting comparison, given that Ghana is currently faced with a yield gap of about 23 percent relative to the global standard, is that the estimated mean TE is similar to that of Nigeria (0.71) (Binam, Gockowski, and Nkamleu 2008) and lower than that of Indonesia (0.82) (Effendy et al. 2019). In terms of regional ranking, unlike Ofori-Bah and Asafu-Adjaye (2011) and Danso-Ajn bbeam and Baiyegunhi 
(2019) who found the Volta and Ashanti regions, respectively, to be least efficient, this study indicated the Western region. Particularly, Figure 4(b) shows that the most technically efficient cocoa farmers relative to their region's production frontier are in the Brong Ahafo region with the TE estimated at 0.80 , followed by Ashanti (0.78), Volta (0.74), Eastern (0.70), Central (0.67), and then Western (0.61). Furthermore, Figure 5 (b) also shows that the TE remained stable below 0.80 .

A major caveat about TE is that it does not tell us about how farmers perform relative to the technology available in Ghana as a whole. The TE of the farmers relative to the overall cocoa production technology in Ghana is given by their MTE, which is the product of the TGR and TE. These are presented in Figures 4(c) and 5(c). The mean MTE indicated that cocoa farmers operated at 56 percent of the potential cocoa output, given the technology available in Ghana. Figure 4(c) shows that the most technically efficient cocoa farmers relative to the overall cocoa production frontier are in the Brong Ahafo region with the MTE estimated at 0.65 , followed by Ashanti $(0.58)$, Volta (0.57), Eastern (0.53), Central (0.52), and Western (0.52). These MTE scores are different from those estimated by Danso-Abbeam and Baiyegunhi (2019).

The study observed that yields are rising in the raw data, but those of the TGR, TE, and MTE changed marginally, averaging about $0.79,0.72$, and 0.56 overtime. This means that regardless of the progress made in cocoa production technology, as shown in the rising yields, Ghana is not likely to achieve its potential cocoa output since farmers are likely adopting technology that is 20 percent less productive than the best technology and are about 30 percent inefficient in using the adopted technology. The temporal (Figure 5(c)) and the spatial (Figure 4(c)) dynamics of the MTE follow closely to that of the TE, indicating that pure technical inefficiency is a chronic source of low cocoa production in Ghana.

All things equal, declining productivity with an aging capital stock of cocoa will mean the production frontier is shrinking inward over time. While the study was unable to satisfactorily account for this in the primary analysis due to sparse data, the limited data show that the age of the capital stock of cocoa is at best constant over time or at worst becoming older, with about 3 percent of the stock annually moving from stages of increased growth in yields to stages of decreased or declining growth in yields. Consequently, the meta-frontier has likely remained constant over time or has shrunk inward. Additionally, at the regional level, the capital stock of cocoa for the Central, Eastern, and Western regions is aging faster than that in Ashanti and Brong Ahafo; thus, one cannot rule out regional differences in the age of the capital stock to account for observed regional differences in the TGR and MTE. This could also account for the diminishing returns to production input like labor as observed in the data.

\section{Alternative policy outcomes}

Given the estimates of the TGR, TE, and MTE, it is possible to increase the overall production of cocoa in Ghana by improving these scores. According to Binam et al. (2008), in the near and medium term, improving the pure TE of farmers via government extension programs and developing rural credit institutions offer the fastest potential gains. On the contrary, minimizing technology gaps (improving the TGR) via investments in the best technological innovations already existing in the country can improve cocoa production in the long term. A compromise between the two is to minimize both technical inefficiency and technology gaps by solely improving the MTE or a combination of the TGR, TE, and MTE. In this section, the study presents the potential outcomes of 
pursuing these alternative policies. The details of the simulation are presented in Supplementary Note A2.

By implementing a nationwide TE maximization policy throughout Ghana, the mean country yield for cocoa in Ghana could increase by 22 percent from 340 to $413 \mathrm{~kg} / \mathrm{ha}$, and the ratio of Ghana's yield to that of the global standard improves from 0.80 to 0.97 . Consequently, the global cocoa supply could increase by 21 percent ceteris paribus. On the contrary, if the GoG embarks on a technology gap minimizing policy (increase the TGR) throughout Ghana, the mean yield could increase by 61 percent, yield ratio improves to 1.29 , and global supply increases by 27 percent. Finally, if the GoG minimizes both technical inefficiency and technology gaps (increase the MTE) throughout Ghana, the mean yield could increase by 94 percent, the yield ratio could improve to 1.55 , and global supply could increase by 33 percent. It is unrealistic that GoG will want to pursue exclusively TE, TGR, or MTE improving policies. A more realistic goal will be to improve the overall yields in Ghana to those of the global standard, particularly to achieve a yield ratio of one. The optimal policy should aim at minimizing both technical inefficiency and technology gap for about 41 percent of the farmers in the Western region. The result of this policy could increase the mean yield and global supply by 25 percent and 21 percent, respectively. These alternative policy outcomes suggest that there is ample room for Ghana to increase its cocoa production by reducing technology gaps, technical inefficiency, or both.

\section{Conclusions}

Cocoa production has evolved into a significant element in the economic development of Ghana, as it accounts for a major share of the income of its producing households and 16 percent of exports. Despite its key contribution, and notwithstanding production improving policies and reforms implemented by GoG and NGOs, Ghana's cocoa yields are about 23 percent below global standards. According to the World Bank, the growth of developing countries is strongly linked to agricultural performance, which is, in turn, dictated by total factor productivity. In the case of Ghana, cocoa is the only single crop contributing about 10 percent to agricultural GDP. Thus, one cannot overemphasize the importance of improving cocoa yields to at least that of the global standard. Consequently, previous studies have attempted to ascertain the productivity and TE of cocoa farmers in Ghana. Considering their limitations of investigating Ghanaian cocoa farmer's TE for a single season, and mostly assuming a homogeneous production technology throughout Ghana, this study extends the literature to accommodate multiple seasons and heterogeneity in technology at the regional level.

The results indicated that the greatest contributor to cocoa production is land, followed by family labor, hired labor, pesticide, and then fertilizer. Cocoa production RTS estimates suggest that long-run average costs could be increasing, an indication of diseconomies of scale. In terms of technology, the results indicated that Ghanaian cocoa farmers use technology that is about 80 percent of the best available in country. The differences in region-specific elasticities and technology gaps suggest that cocoa production structure and technology is regionally not homogeneous; farmers in the Western and Ashanti regions operated with the best and worst technologies, respectively. Holding regional technology constant, cocoa farmers were about 72 percent technically efficient.

Between pure farmer technical inefficiency and regional technology gaps, the results showed that the former is a chronic source of low cocoa production in Ghana. This 
implies that farmers performed poorly relative to the meta-frontier mainly because of their managerial practices. Consequently, this implies that policies targeted at improving farmer's managerial skills could increase output. However, such a blanket policy will not be appropriate for farmers in all regions. Particularly, since they are the most efficient given their regional frontiers, farmers in the Brong Ahafo and Ashanti regions will benefit from technology transfer (e.g., improved planting materials and fertilizer blends) from the Western region. On the contrary, farmers in the Western and Central regions will benefit from training in good cocoa production practices via, for example, farmer field schools. For farmers in the Eastern and Volta regions, a mix of technology and training in good cocoa production practices is in order.

The temporal dimension of the results also shows improvements in Ghana's cocoa production over the forgoing period. This is reflected in the increase in the responsiveness of production to land, minimization of technology gaps, and improvements to the TE of farmers. However, the reduction in the scale of HI-TECH due to poor farmer repayment has likely led to an increase in technology gaps. Thus, the GoG needs to find innovative ways of improving the sustainability of these programs. Particularly, HI-TECH could be heavily targeted at farmers in the Central and Ashanti regions since they are the most constrained in production technology. Finally, there is an opportunity of increasing production by 22 percent, 61 percent, or 94 percent in Ghanaian cocoa production, which is possible just by reducing technology gaps, pure farmer inefficiency, or both, respectively. These improvements could lead to an increased global supply of cocoa that could be as high as 33 percent. A follow-up study of this article could investigate the same dynamics but on a global scale. This could give stakeholders a sense of which interventions to implement, based on chronic sources of production shortfall. A major limitation of this study is the absence of reliable information on the age of trees; thus, future work might consider improving the analysis with such information if possible.

Supplementary material. The supplementary material for this article can be found at https://doi.org/10. 1017/age.2021.3.

Data availability statement. Replication materials are available in GitHub at https:/github.com/ftsiboe/ Agricultural-Productivity-in-Ghana.

Acknowledgment. The author gratefully acknowledges the Centre for the Study of African Economies, Ghana Statistical Service, Economic Growth Center, Institute of Statistical Social and Economic Research, The Royal Tropical Institute (KIT), Tulane University, and the World Cocoa Foundation (WCF) for making the dataset available for the study. All errors and omissions are the responsibility of the author.

\section{References}

Abenyega, O., and J. Gockowski. 2001. "Labor Practices in the Cocoa Sector of Ghana with a Special Focus on the Role of Children." Findings from a 2001 Survey of Cocoa Producing Households. Available at: http://hubrural.org/IMG/pdf/stcp_ghana_labor_practices.pdf (accessed February 20, 2021).

Aigner, D., C.A. Knox Lovell, and P. Schmidt. 1977. "Formulation and Estimation of Stochastic Frontier Production Function Models." Journal of Econometrics 6(1): 21-37, DOI:10.1016/0304-4076(77)90052-5.

Aneani, F., V.M. Anchirinah, M. Asamoah, and F. Owusu-Ansah. 2011. "Analysis of Economic Efficiency in Cocoa Production in Ghana." African Journal of Food, Agriculture, Nutrition and Development 11(1): 1-20.

Aneani, F., and K. Ofori-Frimpong. 2013. "An Analysis of Yield Gap and Some Factors of Cocoa (Theobroma cacao) Yields in Ghana." Sustainable Agriculture Research 2(4): 117, DOI:10.5539/ sar.v2n4p117. 
Battese, G.E., D.S. Prasada Rao, and C.J. O’Donnell. 2004. “A Metafrontier Production Function for Estimation of Technical Efficiencies and Technology Gaps for Firms Operating Under Different Technologies." Journal of Productivity Analysis 21(1): 91-103, DOI:10.1023/B: PROD.0000012454.06094.29.

Battese, G.E., A.N. Rambaldi, and G.H. Wan. 1997. "A Stochastic Frontier Production Function with Flexible Risk Properties.” Journal of Productivity Analysis 8(3): 269-280, DOI:10.1023/ A:1007755604744.

Bellemare, M.F., and C.J. Wichman. 2020. "Elasticities and the Inverse Hyperbolic Sine Transformation." Oxford Bulletin of Economics and Statistics 82(1): 50-61, DOI:10.1111/obes.12325.

Belotti, F., S. Daidone, G. Ilardi, and V. Atella. 2013. "Stochastic Frontier Analysis Using Stata." The Stata Journal 13(4): 719-758.

Besseah, F.H.F.A., and S. Kim. 2014. "Technical Efficiency of Cocoa Farmers in Ghana." Journal of Rural Development/Nongchon-Gyeongje 37(2): 159-182.

Binam, J.N., J. Gockowski, and G.B. Nkamleu. 2008. "Technical Efficiency And Productivity Potential Of Cocoa Farmers In West African Countries." The Developing Economies 46(3): 242-263, DOI:10.1111/ j.1746-1049.2008.00065.x.

Centre for the Study of African Economies (CSAE). 2016. "Ghana Cocoa Farmers Survey Data." Available at: http://www.csae.ox.ac.uk/datasets/Ghana-cocoa/gcfs-main.html (accessed November 12, 2016).

Charnes, A., W.W. Cooper, and E. Rhodes. 1978. "Measuring the Efficiency of Decision Making Units." European Journal of Operational Research 2(6): 429-444, DOI:10.1016/0377-2217(78)90138-8.

Charnes, A., W.W. Cooper, and E. Rhodes. 1981. "Evaluating Program and Managerial Efficiency: An Application of Data Envelopment Analysis to Program Follow Through." Management Science 27(6): 668-697, DOI:10.1287/mnsc.27.6.668.

Coelli, T. 1995. "Estimators and Hypothesis Tests for a Stochastic Frontier Function: A Monte Carlo Analysis." Journal of Productivity Analysis 6(3): 247-268, DOI:10.1007/BF01076978.

Danso-Abbeam, G., and L.J.S. Baiyegunhi. 2019. "Technical Efficiency and Technology Gap in Ghana's Cocoa Industry: Accounting for Farm Heterogeneity." Applied Economics: 1-13, DOI:10.1080/ 00036846.2019.1644439.

Denkyirah, E.K., E.D. Okoffo, D.T. Adu, A.A. Aziz, A. Ofori, and E.K. Denkyirah. 2016. "Modeling Ghanaian Cocoa Farmers' Decision to Use Pesticide and Frequency of Application: The Case of Brong Ahafo Region." SpringerPlus 5(1): 1113, DOI:10.1186/s40064-016-2779-z.

Effendy, M. Fardhal Pratama, R.A. Rauf, M. Antara, M. Basir-Cyio, Mahfudz, and Muhardi. 2019. "Factors Influencing the Efficiency of Cocoa Farms: A Study to Increase Income in Rural Indonesia." PLoS ONE 14(4): e0214569, DOI:10.1371/journal.pone.0214569.

Farrell, M.J. 1957. "The Measurement of Productive Efficiency." Journal of the Royal Statistical Society A 120(3): 253, DOI:10.2307/2343100.

Food and Agriculture Organization (FAO). 2019. "FAOSTAT." Food and Agriculture Organization of the United Nations. Available at: http://faostat.fao.org/ (accessed February 20, 2021).

Ghana Statistical Service (GSS). 2019. "Ghana Living Standards Survey 7 (GLSS 7) Main Report." Available at: https://statsghana.gov.gh/gssmain/fileUpload/pressrelease/GLSS7\%20MAIN\%20REPORT_FINAL.pdf (accessed March 2, 2021).

Gockowski, J., C. Asamoah, S. David, I. Gyamfi, and M.A. Kumi. 2010. "An Evaluation of Farmer Field School Induced Changes in Ghanaian Cocoa Production." Journal of International Agricultural and Extension Education 17(3): 43-56, DOI:10.5191/jiaee.2010.17304.

Gutierrez, R.G., S. Carter, and D.M. Drukker. 2001. "On Boundary-Value Likelihood-Ratio Tests." Stata Technical Bulletin 10(60): 15-18.

Hayami, Y. 1969. "Sources of Agricultural Productivity Gap among Selected Countries." American Journal of Agricultural Economics 51(3): 564, DOI:10.2307/1237909.

Hayami, Y., and V.W. Ruttan. 1970. "Agricultural Productivity Differences among Countries." The American Economic Review, DOI:10.2307/1818289.

Hayami, Y., and V.W. Ruttan. 1971. Agricultural Development: An International Perspective. Baltimore, MD: The Johns Hopkins Press.

Huang, C.J., T.-H. Huang, and N.-H. Liu. 2014. "A New Approach to Estimating the Metafrontier Production Function Based on a Stochastic Frontier Framework." Journal of Productivity Analysis, DOI:10.1007/s11123-014-0402-2. 
Institute of Statistical Social and Economic Research (ISSER), and Economic Growth Center (EGC). 2016. "Ghana - Socioeconomic Panel Survey: 2009-2010.” Microdata Library. GHA_2009_GSPS_v01_M. 2016. Available at: http://microdata.worldbank.org/index.php/catalog/2534 (accessed February 20, 2021).

Just, R.E., and R.D. Pope. 1979. "Production Function Estimation and Related Risk Considerations." American Journal of Agricultural Economics 61(2): 276, DOI:10.2307/1239732.

Kolavalli, S., and M. Vigneri. 2011. "Cocoa in Ghana: Shaping the Success of an Economy." In: P. Chuhan-Pole and M. Angwafo (eds.), Yes, Africa Can: Success Stories from A Dynamic Continent (pp. 201-217). The World Bank, DOI:10.1596/978-0-8213-8745-0.

Kolavalli, S., and M. Vigneri. 2017. "The Cocoa Coast: The Board-Managed Cocoa Sector in Ghana," DOI:10.2499/9780896292680.

Lass, R.A. 2001. "Replanting and Rehabilitation of Old Cocoa Farms." In: G.A.R. Wood, R.A. Lass and Forth (eds.), Cocoa (pp. 210-233). Oxford, UK: Blackwell Science Ltd, DOI:10.1002/9780470698983.

Meeusen, W., and J. van Den Broeck. 1977. "Efficiency Estimation from Cobb-Douglas Production Functions with Composed Error." International Economic Review 18(2): 435, DOI:10.2307/2525757.

Montgomery, P.J. 1981. "Some Thoughts on the Life Span of Cocoa." Planter 57: 604-609.

Norton, M., L. Lanier Nalley, B. Dixon, and J. Popp. 2013. "Cost-Benefit Analysis of Farmer Training In Ghanaian Cocoa Farming." Journal of International Agricultural Trade and Development 9(1): 1-23.

O'Donnell, C.J., D.S. Prasada Prasada Rao, and G.E. Battese. 2008. "Metafrontier Frameworks for the Study of Firm-Level Efficiencies and Technology Ratios." Empirical Economics 34(2): 231-255, DOI:10.1007/s00181-007-0119-4.

Ofori-Bah, A., and J. Asafu-Adjaye. 2011. "Scope Economies and Technical Efficiency of Cocoa Agroforesty Systems in Ghana." Ecological Economics 70(8): 1508-1518, DOI:10.1016/ j.ecolecon.2011.03.013.

Onumah, J.A., E.E. Onumah, R.M. Al-Hassan, and B. Brümmer. 2013. "Meta-Frontier Analysis of Organic and Conventional Cocoa Production in Ghana." Agricultural Economics 59(6): 271-280. doi: 10.17221/128/2012-AGRICECON.

Opoko, E., R. Dzene, S. Caria, F. Teal, and A. Zeitlin. 2009. "Impacts of Group Based Microfinance in Agriculture: Evidence from Ghana's Cocoa Abrabopa Association." Annual Conference of Center for the Study of African Economies (CSAE) 2009. Oxford, UK: University of Oxford. Available at: http://www. csae.ox.ac.uk/conferences/2009-edia/papers/473-CariaTealZeitlin.pdf (accessed February 20, 2021).

Schmidt, P., and T.-F. Lin. 1984. "Simple Tests of Alternative Specifications in Stochastic Frontier Models." Journal of Econometrics 24(3): 349-361, DOI:10.1016/0304-4076(84)90058-7.

Takeshima, H., N. Houssou, and X. Diao. 2018. "Effects of Tractor Ownership on Returns-to-Scale in Agriculture: Evidence from Maize in Ghana." Food Policy 77(May): 33-49, DOI:10.1016/ j.foodpol.2018.04.001.

Teal, F., A. Zeitlin, and H. Maamah. 2006. "Ghana Cocoa Farmers Survey 2004: Report to Ghana Cocoa Board.” Available at: https:/www.researchgate.net/profile/Francis-Teal-2/publication/241205997_Ghana_ Cocoa_Farmers_Survey_2004_Report_to_Ghana_Cocoa_Board/links/54da6ed50cf233119bc33e83/GhanaCocoa-Farmers-Survey-2004-Report-to-Ghana-Cocoa-Board.pdf (accessed March 2, 2021).

Truett, L.J., and D.B. Truett. 1990. "Regions of the Production Function, Returns, and Economies of Scale: Further Considerations." The Journal of Economic Education 21(4): 411-419, DOI:10.1080/ 00220485.1990 .10844687$.

Tsiboe, F., J. Asravor, and E. Osei. 2019. "Vegetable Production Technical Efficiency and Technology Gaps in Ghana." African Journal of Agricultural and Resource Economics 14(4): 255-278.

Tsiboe, F., B.L. Dixon, L.L. Nalley, J.S. Popp, and J. Luckstead. 2016. "Estimating the Impact of Farmer Field Schools in Sub-Saharan Africa: The Case of Cocoa." Agricultural Economics 47(3): 329-339, DOI:10.1111/agec.12233.

Tsiboe, F., J. Luckstead, B.L. Dixon, L.L. Nalley, and J.S. Popp. 2018a. "Analyzing Labor Heterogeneity in Ghanaian Cocoa Production and Its Implications for Separability in Household Decisions and Policy." Journal of Agricultural and Applied Economics: 1-26, DOI:10.1017/aae.2018.18.

Tsiboe, F., J. Luckstead, L.L. Nalley, J.S. Popp, and B.L. Dixon. 2018b. "Market Effects of Farmer Field Schools in Sub-Saharan Africa: The Case for Cocoa." Review of Development Economics 22(4): e160e184, DOI:10.1111/rode.12520.

Tsiboe, F., and L.L. Nalley. 2016. "Effect of Biotic and Abiotic Stress on Household Cocoa Yields in Ghana." African Journal of Agricultural and Resource Economics 11(3): 239-248. 
Tyszler, M., R. Bymolt, and A. Laven. 2018. "Demystifying the Cocoa Sector in Ghana and Côte d'Ivoire." Harvard Dataverse, V2, UNF:6:BKsOmmVySdVxa8Ksq2ajHQ== [FileUNF]. Available at: https://doi. org/https://doi.org/10.7910/DVN/82TWZJ (accessed February 20, 2021).

UN Comtrade. 2020. "United Nations Commodity Trade Statistics Database." Available at: http://comtrade. un.org/data/ (accessed February 20, 2021).

Vigneri, M. 2007. "Drivers of Change in Ghana's Cocoa Sector." IFPRI-GSSP Background Paper n. 13. ODI Project Briefing. Westminster. Available at: https:/www.ifpri.org/cdmref/p15738coll2/id/18214/ filename/18215.pdf (accessed March 2, 2021).

Wood, G.A.R., and R.A. Lass. 1987. Cocoa. London: Longman Scientific \& Technical.

World Bank. 2007. World Development Report 2008. The World Bank, DOI:10.1596/978-0-8213-6807-7.

World Cocoa Foundation. 2021. "Initiatives: World Cocoa Foundation." Available at: https://www.world cocoafoundation.org/initiatives/ (accessed March 2, 2021).

Cite this article: Tsiboe F (2021). Chronic sources of low cocoa production in Ghana: new insights from meta-analysis of old survey data. Agricultural and Resource Economics Review 50, 226-251. https://doi.org/ 10.1017/age.2021.3 